\title{
Age-related trends in genetic parameters for Larix kaempferi and their implications for early selection
}

\author{
Meng Lai, Xiaomei Sun, Dongsheng Chen, Yunhui Xie, Shougong Zhang* \\ From International Symposium on Quantitative Genetics and Genomics of Woody Plants \\ Nantong, China. 16-18 August 2013
}

\begin{abstract}
Background: Japanese larch (Larix kaempferi) has been introduced in China at the end of the $19^{\text {th }}$ century, and as one successful exotic species, is becoming the preferred coniferous in northern China and sub-tropical alpine region. The rotation age is about 25-28 years for L. kaempferi as pulpwood in Henan province. Waiting for even one-half rotation age for final evaluation will be inefficient due to accumulated testing costs and delayed return on investment, which suggests that selection at an early age is highly desirable for L. kaempferi improvement programs in Henan province. In this study, we determined age trends of genetic parameters and evaluated early selection efficiency for $L$. kaempferi in Henan province to find out the appropriate trait for early selection and its selection age.
\end{abstract}

Results: Growth traits of 78 clones were measured periodically from age 2 to age 15 in a clonal trial of Larix kaempferi establishted at Son town, Henan Province. The genetic variation among clones, age-age correlations, and age trends in genetic parameters for growth traits were analyzed. Variant analysis revealed that tree height (HGT) and diameter at breast (DBH) were significant (1\% level) among clones at every ages. The clonal repeatability of growth traits varied year-by-year, reaching the highest levels at different ages for different traits $(0.77$ at age 2 for HGT, 0.70 at age 5 for DBH and 0.66 from age 8 to age 10 for volume, respectively). The age-age genetic correlations ranged from 0.904 to 1.000 for HGT, and from 0943 to 1.000 for DBH. DBH at different ages was more genetically correlated to volume-15 than HGT. At the phenotypic level, HGT was always less correlated to volume15 than DBH. With the estimates of efficiencies of early selection, the recommendation from present study was that the optimum age of early selection was age 2 for HGT and age 5 for DBH.

Conclusions: Our study showed that there were significant (1\% level) on growth traits among clones at every ages. The genetic parameters for growth traits varied from age to age. We found dual trait selection was more efficient than single trait selection for early selection.

\section{Background}

Larch (Larix sp.) is one of the most valuable conifers in boreal and temperate forests as well as in mountainous regions where it is either native or introduced in artificial plantations [1]. It is of great ecological and economical importance and is highly appreciated for wood properties including high mechanical strength, attractive reddish colour and high natural durability. Japanese larch (Larix

\footnotetext{
* Correspondence: shougong.zhang@caf.ac.cn

State Key Laboratory of Tree Genetics and Breeding, Research Institute of Forestry, Chinese Academy of Forestry, Beijing 100091, China
}

kaempferi) has been introduced in China at the end of the $19^{\text {th }}$ century, and as one successful exotic species, is becoming the preferred coniferous in northern China and sub-tropical alpine region due to its superior performance on fast-growing at early ages, higher wood specific gravity, comparable fiber length, pest resistance and wide adaptation [2]. As a result, the area of Japanese larch plantation has been over 0.3 million hectares in China, and has been increasing at a speed of 300 thousand hectares annually. 
The rotation age is about 25-28 years for L. kaempferi as pulpwood in Henan province. Waiting for even onehalf rotation age for final evaluation will be inefficient due to accumulated testing costs and delayed return on investment, which suggests that selection at an early age is highly desirable for L. kaempferi improvement programs in Henan province.

Age trends for genetic parameters are crucial for developing tree breeding strategy and early selection [3]. A number of studies have documented age trends in these parameters for loblolly pine (Pinus. taeda) [4-9], Scots pine (P. sylvestris) [10-12], maritime pine (P. pinaster) [13], lodgepole pine ( $P$. contorta) $[14,15]$, jack pine (P. banksiana) $[16,17,3]$, and Douglas-fir (P. menziesii) $[18,19]$. However, relatively few authors have addressed trends over time in genetic parameters for L. kaempferi. After the analyses of age trends in heritability, juvenile-mature correlations and genetic gains, Sun et al. [20] found that the most proper age for early selection was age 6 , and diameter was a better predictor than height due to its genetic stability. In a clonal trail of L. kaempferi in northern China, Ma et al. [26] found that the Lambeth model generally fit genetic correlations well, and the highest selection efficiency for height was achieved at age 10 by using height at age 20 as selection criterion. The objectives of the study were, on the basis of a clonal trail of L. kaempferi that included 78 clones, (1) to determine age trends of genetic parameters, (2) to estimate age-age correlations for HGT and DBH, (3) to estimate age-age correlations for HGT and DBH with VOL-15, (4) to evaluate early selection efficiency for L. kaempferi in Henan province.

\section{Methods}

\section{Trial description}

The data were collected from a clonal trial established at Son town in Henan $\left(34^{\circ} 14^{\prime} \mathrm{N}, 112^{\circ} 07^{\prime} \mathrm{E}\right)$, and with annual mean temperature of $8.6^{\circ} \mathrm{C}$ and annual rainfall of 800 $1200 \mathrm{~mm}$. Minimum January temperature and maximum July temperature at this region were $-15.5^{\circ} \mathrm{C}$ and $24.7^{\circ} \mathrm{C}$, respectively. The soil was brown earth and $\mathrm{pH}=6.0 .78$ L. kaempferi clones were planted in the spring of 1998. Field design was randomized complete blocks with four replications and 4-tree plot in a spacing of $2 \mathrm{~m} \times 2 \mathrm{~m}$.

\section{Data collection}

Diameter at breast (DBH) and height (HGT) were measured for all trees. HGT was measured from 2 to 15 yeas after planting, and DBH was measured from 5 to 15 years after planting. The traits analysed in this study were referred to as DBH-8, HGT-4 etc, the numbers indicating the ages. Individual tree volume ( $\mathrm{VOL}$ in $\mathrm{m}^{3}$ ) was calculated using the following tree volume formula [22]:

$$
\mathrm{VOL}=0.0000592372 \times \mathrm{DBH}^{1.8655726} \times \mathrm{HGT}^{0.98098962}(1)
$$

\section{Statistical analysis}

In this study, a nonlinear mixed model by using Richards growth function as basic model was constructed to fit the relationship for first-hand data of growth traits on age.

Richards growth function was as followed:

$$
Y=a\left(1-\mathrm{e}^{-b T}\right)^{c}
$$

Where $Y$ is height (HGT) or diameter at breast (DBH), $a, b$ and $c$ are parameters, and $T$ is the age of the trees.

Nonlinear mixed model was as followed:

$$
Y=\left(a+v_{L}+v_{R}\right)\left[1-e^{-\left(b+\omega_{L}+\omega_{R}\right) T}\right]^{c}+\varepsilon
$$

Where $v_{L}$ and $v_{R}$, and $\omega_{L}$ and $\omega_{R}$ are random coefficients at the clone and replication levels for $a$ and $b$, respectively, and $c$ was not allowed to vary randomly. The variance-covariance structures were positive-definite at both the clone $\Psi_{L}$ and replication $\Psi_{R}$ levels, and specified as:

$$
\Psi_{L}=\left(\begin{array}{cc}
\sigma_{v L}^{2} & \sigma_{v \omega L}^{2} \\
\sigma_{v \omega L}^{2} & \sigma_{\omega L}^{2}
\end{array}\right) \quad \text { and } \quad \Psi_{R}=\left(\begin{array}{cc}
\sigma_{v R}^{2} & \sigma_{v \omega R}^{2} \\
\sigma_{v \omega R}^{2} & \sigma_{\omega R}^{2}
\end{array}\right)
$$

and distributed bivariate normally with normal random errors:

$$
\begin{aligned}
& E\left(\begin{array}{l}
v_{L} \\
\omega_{L}
\end{array}\right)=0 \quad v_{\alpha r}\left(\begin{array}{l}
v_{L} \\
\omega_{L}
\end{array}\right)=\left(\begin{array}{cc}
\sigma_{v L}^{2} & \sigma_{v \omega L}^{2} \\
\sigma_{v \omega L}^{2} & \sigma_{\omega L}^{2}
\end{array}\right) \\
& E\left(\begin{array}{l}
v_{R} \\
\omega_{R}
\end{array}\right)=0 \quad v_{\alpha r}\left(\begin{array}{l}
v_{R} \\
\omega_{R}
\end{array}\right)=\left(\begin{array}{cc}
\sigma_{v R}^{2} & \sigma_{v \omega R}^{2} \\
\sigma_{v \omega R}^{2} & \sigma_{\omega R}^{2}
\end{array}\right) \\
& \varepsilon \sim N\left(0, \sigma^{2}\right)
\end{aligned}
$$

At every age, variation among clones, variance components, and genetic parameters were analyzed by analysis of variance, using a linear model [23]:

$$
y_{i j}=\mu+\alpha_{i}+\beta_{j}+\varepsilon_{i j}
$$

where $y_{i j}$ is the performance of the $i$ th clone within the $j$ th block, and $\mu$ is the general mean, $\alpha_{i}$ is the effect of the $i$ th clone, $\beta_{j}$ is the effect of the $j$ th block, and $\varepsilon_{i j}$ is the random error.

The repeatability of clonal mean, which refers to genotypic heritability, was estimated as [23]:

$$
R=\sigma_{\mathrm{c}}^{2} / \sigma_{p}^{2}=\sigma_{\mathrm{c}}^{2} /\left(\sigma_{\mathrm{c}}^{2}+\sigma_{e}^{2} / r\right)
$$

Where $r$ is the number of blocks, $\sigma_{p}^{2}$ is the phenotype variance, $\sigma_{\mathrm{c}}^{2}$ is the variance of clone, and $\sigma_{e}^{2}$ is the residual variance. 
The genetic variation coefficient was calculated using the following formula [24]:

$$
\operatorname{CVG}(\%)=100 \times \sqrt{\sigma_{c}^{2}} / \bar{X}
$$

Where $\bar{X}$ is the trait average phenotypic mean. The equation expresses a standardized measure of the genetic variance relative to the mean of trait.

The selection gain among clones was estimated by:

$$
\Delta G(\%)=100 \times i R \sigma_{p} / \bar{X}
$$

Where $i$ is the standardized selection intensity, $R$ is the repeatability, and $\sigma_{p}$ is the phenotypic standard deviation.

The phenotypic correlation of two traits (same traits at different ages were treated as different traits) was calculated as:

$$
r_{p}=\sigma_{p(x y)} / \sqrt{\sigma_{p(x)}^{2} \times \sigma_{p(y)}^{2}}
$$

where $\sigma_{p(x y)}$ is the phenotype covariance component between traits $x$ and $y, \sigma_{p(x)}^{2}$ is the phenotype variance component for trait $x$ and $\sigma_{p(y)}^{2}$ is the phenotype variance component for trait $y$.

The genotypic correlation of two traits (same traits at different ages were treated as different traits) was calculated as [23]:

$$
r_{g}=\sigma_{c(x y)} / \sqrt{\sigma_{c(x)}^{2} \times \sigma_{c(y)}^{2}}
$$

where $\sigma_{c(x y)}$ is the clone covariance component between traits $x$ and $y, \sigma_{c(x)}^{2}$ is the clone variance component for trait $x$ and $\sigma_{c(y)}^{2}$ is the clone variance component for trait $y$.
Efficiency of early forward selection was examined by taking growth traits at age 15(HGT-15, DBH-15, and VOL-15) as the target traits to be improved. Assuming equal intensity of selection at target and young ages, the selection efficiency $\left(Q_{\text {year }}\right)$, expressed as the ratio of correlated response in trait $y$ at age $T_{2}$ from a selection on trait $x$ at age $T_{1}$ per year, was calculated as [19]:

$$
Q_{\text {year }}=r_{g} \sqrt{R_{x}} T_{2} / \sqrt{R_{y}} T_{1}
$$

Where $T_{1}$ and $T_{2}$ are the ages for trait $x$ and target trait $y$, respectively, $r_{g}$ is the calculated genetic correlation between trait $x$ at $T_{1}$ and trait $y$ at $T_{2}$, and $\sqrt{R_{x}}$ and $\sqrt{R_{y}}$ are the square roots of clonal repeatability for trait $x$ at $T_{1}$ and trait $y$ at $T_{2}$, respectively. A time lag of 6 years for breeding phase was usually assumed for L. kaempferi in Henan province.

\section{Results \\ Model fitting}

The results of the model fitting for growth data of 78 clones are presented in table 1 . The fixed parameters were significant $(p<0.01)$. The random effects of growth equation for HGT and DBH were reflected in maximum value of growth (parameter a) and growth rate (parameter $b$ ), reflecting the differences on the maximum value of growth and growth rate were significant among clones and replications. RMSE and $\mathrm{R}^{2}$ were 0.5961 and $0.9543,0.7134$ and 0.9395 for HGT and $\mathrm{DBH}$, respectively, and the results showed that the nonlinear mixed model fit well.

\section{Phenotypic variation}

Mean values, ranges and $F$ values for growth traits at different ages are presented in table 2. Over the period

\begin{tabular}{|c|c|c|c|c|c|c|c|c|c|}
\hline \multicolumn{2}{|c|}{ Model } & \multicolumn{4}{|c|}{ HGT } & \multicolumn{4}{|c|}{$\mathrm{DBH}$} \\
\hline Fixed effects & Parameters & Estimated values & Std. Dev & $T$ value & $P$ value & Estimated values & Std. Dev & T value & $P$ value \\
\hline & a & 10.9349 & 0.2444 & 44.7408 & $<0.01$ & 9.0885 & 0.2113 & 43.0086 & $<0.01$ \\
\hline & $b$ & 0.1436 & 0.0045 & 31.8415 & $<0.01$ & 0.2489 & 0.0087 & 28.4580 & $<0.01$ \\
\hline & c & 2.2299 & 0.0497 & 44.8156 & $<0.01$ & 5.3868 & 0.2946 & 18.2851 & $<0.01$ \\
\hline \multirow[t]{6}{*}{ Random effects } & $\sigma_{v L}$ & 0.9082 & & & & 0.9761 & & & \\
\hline & $\sigma_{\omega L}$ & 0.0113 & & & & 0.0112 & & & \\
\hline & $\sigma_{v R}$ & 2.4430) & & & & 2.1190 & & & \\
\hline & $\sigma_{\omega R}$ & 0.0157 & & & & 0.0292 & & & \\
\hline & $\sigma_{v \omega L}$ & -0.00641 & & & & -0.00061 & & & \\
\hline & $\sigma_{v \omega R}$ & -0.0240 & & & & -0.0341 & & & \\
\hline \multirow[t]{4}{*}{ Fit statistics } & $R^{2}$ & 0.9543 & & & & 0.9295 & & & \\
\hline & RMSE & 0.5961 & & & & 0.7134 & & & \\
\hline & AIC & 34744.47 & & & & 32408.32 & & & \\
\hline & $\mathrm{BIC}$ & 34803.12 & & & & 32464.59 & & & \\
\hline
\end{tabular}
studied, mean values of the HGT increased from $0.50 \mathrm{~m}$

Table 1 The model parameters, variance components for random effects, and fit statistics for the nonlinear mixed model described in the text (Std. Dev = standard deviation). Fit statistics include the coefficient of determination $\left(R^{2}\right)$, root mean squared error (RMSE), Akaike information criterion (AIC), and Bayesian criterion (BIC). 
Table 2 Mean values, ranges and $\mathrm{F}$ values (**Significant at 0.01 level) for the growth traits at different ages (s.e. = standard error).

\begin{tabular}{|c|c|c|c|c|c|c|}
\hline Traits & Age & Mean & Minimum & Maximum & s.e. & F Value \\
\hline HGT & 2 & 0.50 & 0.29 & 0.86 & 0.0121 & $4.35^{* *}$ \\
\hline \multirow[t]{13}{*}{$(\mathrm{m})$} & 3 & 1.06 & 0.62 & 1.79 & 0.0244 & $4.20^{* *}$ \\
\hline & 4 & 1.73 & 1.02 & 2.88 & 0.0382 & $4.05^{* *}$ \\
\hline & 5 & 2.47 & 1.46 & 4.02 & 0.052 & $4.00^{* *}$ \\
\hline & 6 & 3.21 & 1.91 & 5.16 & 0.0655 & $3.77^{* *}$ \\
\hline & 7 & 3.95 & 2.37 & 6.25 & 0.0775 & $3.63^{* *}$ \\
\hline & 8 & 4.66 & 2.80 & 7.26 & 0.0884 & $3.49^{* *}$ \\
\hline & 9 & 5.33 & 3.22 & 8.18 & 0.0979 & $3.37^{* *}$ \\
\hline & 10 & 5.94 & 3.60 & 9.01 & 0.1062 & $3.25^{* *}$ \\
\hline & 11 & 6.51 & 3.95 & 9.74 & 0.1133 & $3.14^{* *}$ \\
\hline & 12 & 7.01 & 4.28 & 10.39 & 0.1196 & $3.05^{* *}$ \\
\hline & 13 & 7.47 & 4.57 & 10.96 & 0.1249 & $2.96^{* *}$ \\
\hline & 14 & 7.89 & 4.84 & 11.46 & 0.1294 & $2.88^{* *}$ \\
\hline & 15 & 8.25 & 5.07 & 11.89 & 0.1334 & $2.81^{* *}$ \\
\hline DBH & 5 & 1.50 & 0.72 & 2.89 & 0.0457 & $3.28^{* *}$ \\
\hline \multirow[t]{10}{*}{$(\mathrm{cm})$} & 6 & 2.35 & 1.19 & 4.36 & 0.0662 & $3.26^{* *}$ \\
\hline & 7 & 3.26 & 1.71 & 5.82 & 0.0851 & $3.27^{* *}$ \\
\hline & 8 & 4.15 & 2.24 & 7.18 & 0.1015 & $3.26^{* *}$ \\
\hline & 9 & 4.97 & 2.76 & 8.37 & 0.1148 & $3.24^{* *}$ \\
\hline & 10 & 5.69 & 3.23 & 9.38 & 0.1254 & $3.20^{* *}$ \\
\hline & 11 & 6.32 & 3.65 & 10.21 & 0.1334 & $3.16^{* *}$ \\
\hline & 12 & 6.85 & 4.03 & 10.88 & 0.1395 & $3.11^{* *}$ \\
\hline & 13 & 7.29 & 4.34 & 11.41 & 0.1441 & $3.06^{* *}$ \\
\hline & 14 & 7.64 & 4.61 & 11.83 & 0.1476 & $3.01^{* *}$ \\
\hline & 15 & 7.94 & 4.83 & 12.16 & 0.1502 & $2.97^{* *}$ \\
\hline VOL & 5 & 4.15E-04 & $5.78 \mathrm{E}-05$ & 1.99E-03 & 3.44E-05 & $2.74^{* *}$ \\
\hline \multirow[t]{10}{*}{$\left(m^{3}\right)$} & 6 & $1.20 \mathrm{E}-03$ & $1.88 \mathrm{E}-04$ & $5.32 \mathrm{E}-03$ & $9.13 \mathrm{E}-05$ & $2.81^{* *}$ \\
\hline & 7 & 2.63E-03 & 4.46E-04 & $1.07 E-02$ & 1.83E-04 & $2.87^{* *}$ \\
\hline & 8 & 4.73E-03 & 8.62E-04 & 1.80E-02 & 3.07E-04 & $2.91^{* *}$ \\
\hline & 9 & 7.41E-03 & $1.44 \mathrm{E}-03$ & $2.67 E-02$ & 4.52E-04 & $2.92^{* *}$ \\
\hline & 10 & 1.04E-02 & $2.14 \mathrm{E}-03$ & $3.58 \mathrm{E}-02$ & $6.05 \mathrm{E}-04$ & $2.91^{* *}$ \\
\hline & 11 & 1.37E-02 & 2.93E-03 & $4.48 \mathrm{E}-02$ & 7.57E-04 & $2.89^{* *}$ \\
\hline & 12 & $1.71 \mathrm{E}-02$ & 3.77E-03 & $5.34 \mathrm{E}-02$ & 9.01E-04 & $2.86^{* *}$ \\
\hline & 13 & 2.02E-02 & 4.61E-03 & $6.11 \mathrm{E}-02$ & $1.03 \mathrm{E}-03$ & $2.82^{* *}$ \\
\hline & 14 & $2.32 \mathrm{E}-02$ & 5.41E-03 & $6.80 \mathrm{E}-02$ & 1.15E-03 & $2.78^{* *}$ \\
\hline & 15 & $2.58 \mathrm{E}-02$ & $6.17 \mathrm{E}-03$ & 7.39E-02 & $1.25 \mathrm{E}-03$ & $2.74^{* *}$ \\
\hline
\end{tabular}

at age 2 to $8.25 \mathrm{~m}$ at age 15 , the $\mathrm{DBH}$ increased from $1.50 \mathrm{~cm}$ at age 5 to $7.94 \mathrm{~cm}$ at age 15 , and the VOL increased from $0.000415 \mathrm{~m}^{3}$ at age 5 to $0.0258 \mathrm{~m}^{3}$ at age 15. Meanwhile, the annual HGT increment was a mean of $0.60 \mathrm{~m}$, the annual average $\mathrm{DBH}$ and $\mathrm{VOL}$ increment were $6.4 \mathrm{~mm}$ and $0.002538 \mathrm{~m}^{3}$, respectively. The results of the analysis of variance for growth traits showed that there were significant differences (1\% level) on HGT, DBH and VOL among clones at every age, indicating that there were great potential for genetic improvement of growth traits among clones.

\section{Age trends in genetic parameters}

Age trends in variance components, genetic variation coefficients (CVG), clonal repeatability (R) and genetic gains $(\Delta \mathrm{G})$ for growth traits are shown in table 3. Variance components for growth traits showed a clear pattern of change with time, they were increased with aging. It is evident that the variance components of HGT and DBH were higher than those of VOL for all ages. The coefficients of variation at the clonal level (table 3 ) were, in general, ranging between 11.47 and 18.65 percent for HGT, between

Table 3 The variances associated with clone $\left(\sigma_{c}^{2}\right)$, residual error $\left(\sigma_{e}^{2}\right)$ and phenotype $\left(\sigma_{p}^{2}\right)$, genetic variation coefficients (CVG), clonal repeatability (R) and genetic gains $(\Delta G)$ with $5 \%$ selection rate for the growth traits at different ages.

\begin{tabular}{|c|c|c|c|c|c|c|c|}
\hline Traits & Age & $\sigma_{c}^{2}$ & $\sigma_{e}^{2}$ & $\sigma_{p}^{2}$ & CVG (\%) & R & $\Delta \mathrm{G}(\%)$ \\
\hline \multirow[t]{14}{*}{ HGT } & 2 & 0.0087 & 0.0104 & 0.0113 & 18.65 & 0.77 & 33.77 \\
\hline & 3 & 0.0353 & 0.0441 & 0.0463 & 17.72 & 0.76 & 31.92 \\
\hline & 4 & 0.0855 & 0.1121 & 0.1135 & 16.90 & 0.75 & 30.26 \\
\hline & 5 & 0.1586 & 0.2117 & 0.2102 & 16.12 & 0.75 & 28.65 \\
\hline & 6 & 0.2445 & 0.3540 & 0.3335 & 15.40 & 0.73 & 27.27 \\
\hline & 7 & 0.3396 & 0.5168 & 0.4688 & 14.75 & 0.72 & 25.90 \\
\hline & 8 & 0.4353 & 0.6978 & 0.6098 & 14.16 & 0.71 & 24.68 \\
\hline & 9 & 0.5262 & 0.8893 & 0.7485 & 13.61 & 0.70 & 23.54 \\
\hline & 10 & 0.6094 & 1.0832 & 0.8802 & 13.14 & 0.69 & 22.56 \\
\hline & 11 & 0.6839 & 1.2760 & 1.0029 & 12.70 & 0.68 & 21.64 \\
\hline & 12 & 0.7494 & 1.4646 & 1.1156 & 12.35 & 0.67 & 20.88 \\
\hline & 13 & 0.8057 & 1.6447 & 1.2169 & 12.02 & 0.66 & 20.17 \\
\hline & 14 & 0.8534 & 1.8150 & 1.3072 & 11.71 & 0.65 & 19.52 \\
\hline & 15 & 0.8947 & 1.9749 & 1.3884 & 11.47 & 0.64 & 18.99 \\
\hline \multirow[t]{11}{*}{ DBH } & 5 & 0.1136 & 0.1991 & 0.1634 & 22.47 & 0.70 & 38.65 \\
\hline & 6 & 0.2368 & 0.4191 & 0.3416 & 20.71 & 0.69 & 35.57 \\
\hline & 7 & 0.3928 & 0.6924 & 0.5659 & 19.23 & 0.69 & 33.04 \\
\hline & 8 & 0.5576 & 0.9855 & 0.8040 & 17.99 & 0.69 & 30.91 \\
\hline & 9 & 0.7116 & 1.2699 & 1.0291 & 16.97 & 0.69 & 29.12 \\
\hline & 10 & 0.8426 & 1.5308 & 1.2253 & 16.13 & 0.69 & 27.60 \\
\hline & 11 & 0.9484 & 1.7586 & 1.3881 & 15.41 & 0.68 & 26.28 \\
\hline & 12 & 1.0300 & 1.9544 & 1.5186 & 14.82 & 0.68 & 25.17 \\
\hline & 13 & 1.0905 & 2.1198 & 1.6205 & 14.32 & 0.67 & 24.24 \\
\hline & 14 & 1.1361 & 2.2572 & 1.7004 & 13.95 & 0.67 & 23.53 \\
\hline & 15 & 1.1673 & 2.3724 & 1.7604 & 13.61 & 0.66 & 22.86 \\
\hline \multirow[t]{11}{*}{ VOL } & 5 & 5.86E-08 & $1.34 \mathrm{E}-07$ & $9.21 \mathrm{E}-08$ & 58.33 & 0.64 & 95.99 \\
\hline & 6 & $4.18 \mathrm{E}-07$ & $9.28 \mathrm{E}-07$ & $6.50 \mathrm{E}-07$ & 53.88 & 0.64 & 89.13 \\
\hline & 7 & $1.72 \mathrm{E}-06$ & $3.68 \mathrm{E}-06$ & 2.64E-06 & 49.87 & 0.65 & 83.04 \\
\hline & 8 & 4.85E-06 & $1.02 \mathrm{E}-05$ & 7.40E-06 & 46.56 & 0.66 & 77.76 \\
\hline & 9 & $1.05 \mathrm{E}-05$ & $2.18 \mathrm{E}-05$ & $1.60 \mathrm{E}-05$ & 43.73 & 0.66 & 73.20 \\
\hline & 10 & 1.87E-05 & 3.93E-05 & $2.85 \mathrm{E}-05$ & 41.58 & 0.66 & 69.45 \\
\hline & 11 & 2.93E-05 & $6.20 \mathrm{E}-05$ & 4.48E-05 & 39.51 & 0.65 & 65.92 \\
\hline & 12 & 4.12E-05 & 8.87E-05 & $6.34 \mathrm{E}-05$ & 37.54 & 0.65 & 62.44 \\
\hline & 13 & 5.37E-05 & 1.18E-04 & 8.32E-05 & 36.28 & 0.65 & 60.13 \\
\hline & 14 & $6.62 \mathrm{E}-05$ & $1.48 \mathrm{E}-04$ & $1.03 \mathrm{E}-04$ & 35.07 & 0.64 & 57.95 \\
\hline & 15 & 7.79E-05 & 1.79E-04 & 1.23E-04 & 34.21 & 0.64 & 56.24 \\
\hline
\end{tabular}


13.61 and 22.47 percent for DBH and between 34.21 and 58.33 percent for VOL. For all ages, the CVG of VOL was higher than those of HGT and DBH, and the CVG of DBH was higher than the CVG of HGT at the same age. A decreasing trend with age for growth traits was found for CVG in our studies.

The clonal repeatability ranged from 0.64 to 0.77 for HGT with the highest occurring at age 2, from 0.66 to 0.70 for DBH with the highest occurring at age 5 , and from 0.64 to 0.66 for VOL with the highest occurring from age 8 to age 10 . On the whole, the clonal repeatability of HGT and DBH were decreased with ageing, as the clonal repeatability of VOL increased from 0.64 at age 5 to 0.66 at age 8 , keep it at this level until age 10, and then decreased again. Time trends in genetic gains for grow traits among clones selection, with $5 \%$ selection rate (or intensity $=2.063$ ), showed that the greatest gains were reached at age 2 for HGT and age 5 for both DBH and VOL.

Estimated age-age genetic correlations between HGT at different ages and HGT-15 varied from 0.904 to 1.000 (table 4). The corresponding estimated age-age phenotypic correlations ranged from 0.887 to 1.000 . Age-age genetic correlations for DBH varied from 0.943 to 1.000 . For all ages, the DBH were more genetically correlated to DBH-15 than HGT to HGT-15. Phenotypic correlations for DBH ranged from 0.905 to 1.000 , and were generally lower than corresponding genetic correlations estimates for all ages. As the age difference decreased, both the age-age genetic and phenotypic correlations for HGT or DBH increased.

Table 4 Estimated genetic correlations $\left(r_{g}\right)$ and phenotypic correlations $\left(r_{p}\right)$, for height at age 15 (HGT15) with various heights, and diameter at age 15 with various diameters.

\begin{tabular}{ccccc}
\hline Age & \multicolumn{3}{c}{ HGT } & \multicolumn{2}{c}{$\mathrm{DBH}$} \\
\hline 2 & $r_{\mathrm{g}}$ & $r_{\mathrm{p}}$ & $r_{\mathrm{g}}$ & $r_{\mathrm{p}}$ \\
3 & 0.904 & $0.887^{* *}$ & - & - \\
4 & 0.917 & $0.906^{* *}$ & - & - \\
5 & 0.928 & $0.920^{* *}$ & - & - \\
6 & 0.939 & $0.934^{* *}$ & 0.943 & $0.905^{* *}$ \\
7 & 0.950 & $0.947^{* *}$ & 0.956 & $0.926^{* *}$ \\
8 & 0.960 & $0.958^{* *}$ & 0.966 & $0.944^{* *}$ \\
9 & 0.970 & $0.969^{* *}$ & 0.976 & $0.960^{* *}$ \\
10 & 0.978 & $0.977^{* *}$ & 0.983 & $0.973^{* *}$ \\
11 & 0.985 & $0.985^{* *}$ & 0.989 & $0.983^{* *}$ \\
12 & 0.990 & $0.990^{* *}$ & 0.994 & $0.990^{* *}$ \\
13 & 0.995 & $0.995^{* *}$ & 0.997 & $0.995^{* *}$ \\
14 & 0.997 & $0.997^{* *}$ & 0.999 & $0.998^{* *}$ \\
15 & 0.999 & $0.999^{* *}$ & 1.000 & $0.999^{* *}$ \\
\hline$*$ & 1.000 & $1.000^{* *}$ & 1.000 & $1.000^{* *}$ \\
\hline
\end{tabular}

**Significant at 0.01 level.
Estimated of genetic correlations and phenotypic correlations between VOL-15 and various HGT or DBH are listed in table 5 . The genetic and phenotypic correlations involving VOL-15 and various HGT increased with ageing, and the values ranged from 0.849 to 1.000 . The same trend was observed for genetic and phenotypic correlations between VOL-15 and various DBH (rang $0.897-1.000$ ). It is evident that the genetic correlations between DBH and VOL-15 were stronger than corresponding correlations with HGT at the same age. At the phenotypic level, HGT was always less correlated to VOL-15 than DBH.

\section{Efficiencies of early selection}

The efficiencies of early selection $\left(Q_{\text {year }}\right)$ in growth traits at age 15 , through early selection on various HGT and DBH, are shown in Figure 1 and 2, respectively. Although the magnitudes of the selection efficiency varied with time, study indicated that selection made at the first measurement year would be more efficient than direct growth traits selection at age 15 . That is, indirect selection on HGT -2 and DBH- 5 could be expected to produce the most gain per year in growth traits at age-15 compared with direct selection on HGT and DBH themselves.

\section{Discussion}

The variance components, genetic variation coefficients (CVG), clonal repeatability $(R)$ and genetic gains $(\Delta G)$ for growth traits are dynamic during whole period of tree growth and show some certain rules. An increasing trend with age of variance components for growth traits was found in this study, this trend in variance components

Table 5 Estimated genetic correlations $\left(r_{g}\right)$ and phenotypic correlations $\left(r_{p}\right)$, for tree volume at age-15 (VOL-15) with various heights or diameters.

\begin{tabular}{ccccc}
\hline Age & \multicolumn{3}{c}{ HGT } & \multicolumn{3}{c}{ DBH } \\
\hline & $r_{g}$ & $r_{p}$ & $r_{g}$ & $r_{p}$ \\
2 & 0.882 & $0.849^{* *}$ & - & - \\
3 & 0.890 & $0.867^{* *}$ & - & - \\
4 & 0.917 & $0.879^{* *}$ & - & - \\
5 & 0.919 & $0.889^{* *}$ & 0.923 & $0.897^{* *}$ \\
6 & 0.926 & $0.899^{* *}$ & 0.935 & $0.912^{* *}$ \\
7 & 0.942 & $0.908^{* *}$ & 0.943 & $0.925^{* *}$ \\
8 & 0.944 & $0.915^{* *}$ & 0.952 & $0.936^{* *}$ \\
9 & 0.955 & $0.922^{* *}$ & 0.960 & $0.945^{* *}$ \\
10 & 0.955 & $0.927^{* *}$ & 0.964 & $0.951^{* *}$ \\
11 & 0.964 & $0.930^{* *}$ & 0.965 & $0.955^{* *}$ \\
12 & 0.964 & $0.932^{* *}$ & 0.971 & $0.957^{* *}$ \\
13 & 0.964 & $0.933^{* *}$ & 0.971 & $0.958^{* *}$ \\
14 & 0.969 & $0.934^{* *}$ & 0.972 & $0.958^{* *}$ \\
15 & 0.969 & $0.934^{* *}$ & 0.972 & $0.958^{* *}$ \\
\hline
\end{tabular}

**Significant at 0.01 level. 


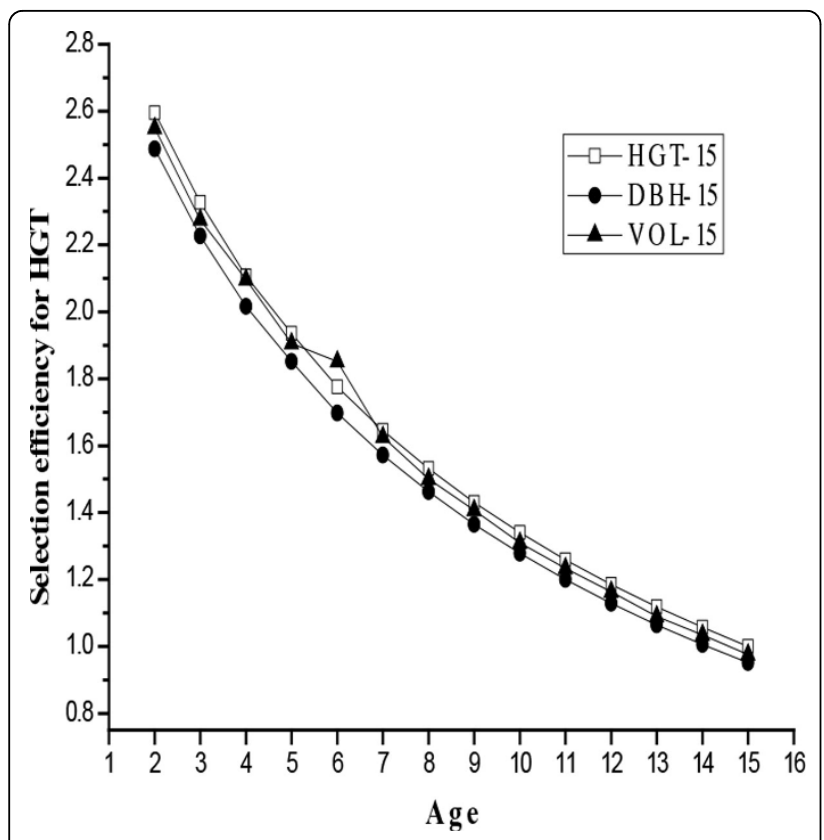

Figure 1 Selection efficiency $\left(Q_{\text {year }}\right)$ for HGT, expressed as the ratio of correlated response in growth traits at age 15 from a selection on various heights.

was similar to those found in Norway spruce [25] and Scots pine [10].

Grasping the age trends of genetic variation coefficients, clonal repeatability and genetic gains are very important for determining the appropriate early selection

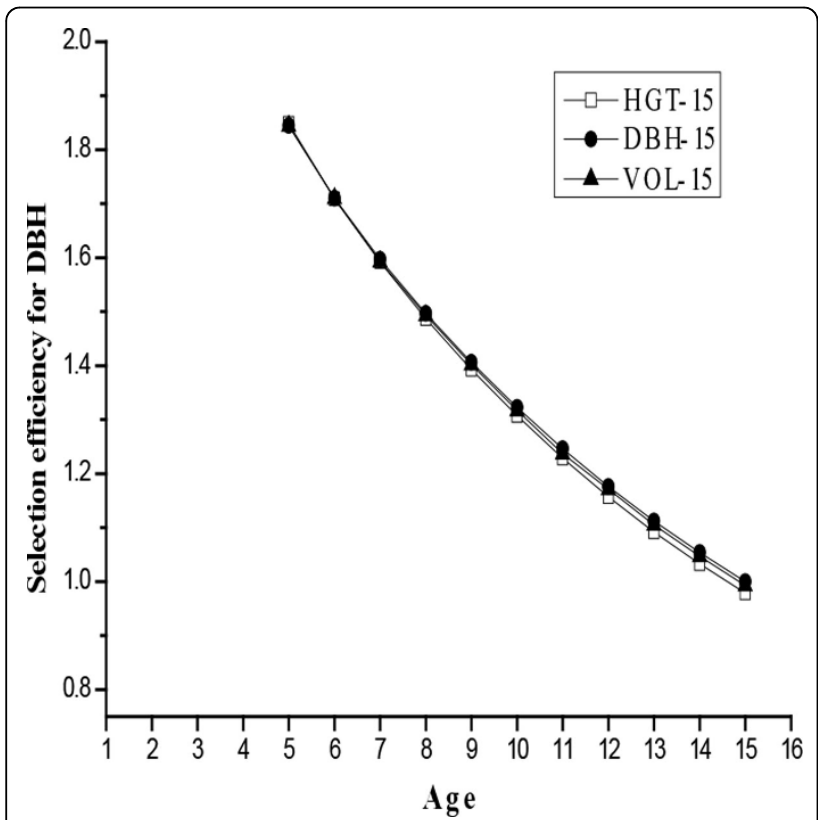

Figure 2 Selection efficiency $\left(Q_{\text {year }}\right)$ for DBH, expressed as the ratio of correlated response in growth traits at age 15 from a selection on various diameters. time and estimating the effects of early selection [26]. The coefficients of genetic variation (CVG), that is, the genetic variance standardized to trait mean, is considered to be the most suitable parameter for comparisons of genetic variation and the ability to respond to natural or artificial selection [27]. In the present study, the CVG of VOL was higher than the CVG of HGT or DBH at the same age, agreeing with previous study of jack pine which revealed that the CVA (additive genetic coefficient of variation) for volume, at one-half rotation age was almost 2-3 times higher as that for height [3]. Besides, the CVG of DBH was higher than the CVG of HGT at the same age, indicating that the scope for selection among clones of DBH is larger than that for HGT. The CVG for growth traits decreased with ageing, with regarded to the CVA, similar trend has been reported in other studies $[10,11,28,29]$.

Clonal repeatability estimates for growth traits in this study ranged from 0.64 to 0.77 , which means that variation in growth traits of L. kaempferi were controlled genetically at medium or upwards level. As a whole, the clonal repeatability of HGT decreased with ageing, agreeing with previous study by Vasquez and Dvorak [30]. Vasquez and Dvorak [30] investigated the trend of heritability for height in tropical pine species during first 8 years of growth, and found that in P. tecunumanii and $P$. chiapensis the heritability of height was decreased with aging. However, Xiang et al. [8] found that the general trend of heritability estimates was increasing over time. Danjon [31] found that the heritability of height in $P$. pinaster increased after 5 years and remained fairly constant after age 10 years. The clonal repeatability of DBH followed a similar trend over time as HGT, which decreased with increasing age, in agreement with former finding in lodgepole pine [15]. Nevertheless, with regard to the heritability in other studies, Jonson et al. [18] found that the heritability of diameter showed an increase with aging for Douglas-fir while the heritability of height was mostly stable over time. Xiang et al. [8] reported that the heritability of diameter increased from age 4 to age 8 . The clonal repeatability of VOL was mostly stable over time, ranging from 0.64 to 0.66 , the values of clonal repeatability for VOL were a few points lower than those of HGT and DBH, reflecting the influence of HGT and DBH on VOL.

Age-age genetic correlations for HGT or DBH in this study were impressive high, and the results suggest that the genes involved in early age HGT or DBH growth appear to be similar to those affecting the same trait at age 15 . The age-age genetic correlations for DBH were stronger than those of HGT for all ages, differed from those of Gwaze and Bridgewater [6] who revealed that at young ages $(<8$ years) height was more genetically correlated to height at 25 years than diameters to diameter at 25 years. 
Dean and Stonecypher [19] found that, from age 5 to age 10 , the genetic correlations involving height and height-17 were stronger than the genetic correlations between diameter and diameter-17 at the same age.

Age-age genetic correlations between various HGT or DBH and VOL at age 15 (VOL-15) were strong. In general, the age-age genetic correlations presented here are similar to other findings in Douglas-fir [18], Norway spruce [25]. The age trend of age-age genetic correlations between various HGT and VOL-15 was similar to the age trend of genetic correlations between various $\mathrm{DBH}$ and VOL-15, which increased with ageing. The results in this study were different from the observations in loblolly pine, in which Xiang et al. [8] reported that the shape of the trend curve over time for genetic correlations of trait height with age- 8 volume was different than the corresponding curve for genetic correlations of trait diameter with age- 8 volume. Age-age genetic correlations between the various HGT and VOL-15 were lower than those between DBH and VOL-15 for all ages. Our results in agreement with those of $\mathrm{Li}$ and Mckeand [32] who found that genetic correlations between various heights and volume at age 20 were always lower than those of between the various diameters and volume at age 20 . However, Gwaze and Bridgewater [6] found that at young ages $(<7$ years) height was more genetically correlated to volume at 25 years than diameter.

It is believed that the age when efficiency of early selection reached the maximum value was the optimum age for early selection [33]. In this study we have used growth traits at age 15 as the selection criterion, results in the present study indicate that early selection for L. kaempferi in Henan province could be effective. High genetic correlations between growth traits at age 15 and various HGT or DBH should explain the observation. In our studies, the optimum selection age for HGT using growth traits at age 15 as selection criterion (age 2) was 3 years lower than those for DBH using growth traits at age 15 as selection criterion (age 5). Although the highest selection efficiency was achieved at the first measurement year, i.e., age 2 for HGT and age 5 for $\mathrm{DBH}$, the true optimal age could potentially be even earlier. Optimum selection age for DBH in this study was slightly lower those estimated by Sun et al. [20] and Ding et al. [34] (6-7 years for family selection). A latter early selection age for HGT of L. kaempferi was found in the study of Ma et al. [21], in which the optimum age of early selection for HGT was age 10 in northern of China.

Some researchers thought the superiority of height for early selection was due to its higher heritability than diameter [35-37]. However, $\mathrm{Li}$ and Mckeand [32] inferred that optimum selection age for diameter was likely to be lower than that of height given the higher age-age correlations and the comparable heritability estimates, and thus diameter should be more effective than height as the trait for early selection. In this study, the efficiencies $\left(\mathrm{Q}_{\text {year }}\right)$ of early selection on HGT at young ages $(<10$ years) in terms of indirect gains per year in vol-15 were higher than those for DBH, suggesting that HGT might be a better early selection criterion than DBH. However, with the analyses of age trends for HGT and DBH in genetic parameters, we found DBH was a better predictor than HGT. These results indicate that dual trait selection might be more reliable than single trait selection for early selection, agreeing well with results for China fir (Cunninghamia. Lanceolata) published elsewhere [21,38].

The strength of this study is that the population sample size was large (78 clones) and a nonlinear mixed model was used to fit the relationship for first-hand data of HGT and DBH on age, therefore allowed reasonably precise genetic statistics and realistic predictions of rotation age gains. However, the study is limited by the fact that it was established at only one site. The genetic parameters and age-age correlations have been shown to differ among sites or geographic regions $[3,4]$.

\section{Conclusions}

In conclusion, there were significant differences (1\% level) on growth traits among clones at every ages. The genetic parameters for growth traits varied from age to age. The genetic correlations involving VOL-15 and various HGT or DBH increased with ageing, and HGT was always less correlated to VOL-15 than DBH at the genetic level. Using growth traits at age 15 as the selection criterion, the highest selection efficiency was achieved at the first measurement year, thus the optimal selection age was age 2 for $\mathrm{HGT}$ and age 5 for $\mathrm{DBH}$, and dual trait selection was more efficient than single trait selection for early selection.

\section{Competing interests}

The authors declare that they have no competing interests.

\section{Authors' contributions}

ML conducted the study and wrote the manuscript. XM Sun carried out the critical reading and grammatical correction of manuscript. SG Zhang was mainly responsible for who gained the fund providing the study need. DS Chen and $\mathrm{YH}$ Xie participated in discussions and helped to draft the manuscript. All authors read and approved the final manuscript.

\section{Acknowledgements}

The authors gratefully thank professor CG Ma for providing review comments on early draft of this paper, K Zhao from Luoyang Forest Institute for his painstaking in data collection. This work was supported by the National Science \& Technology Pillar Program in the Twelfth Five-Year Plan Period of China (2012BAD01B01).

\section{Declarations}

Publication charges for this work were funded by a grant from the National Science \& Technology Pillar Program in the Twelfth Five-Year Plan Period of China (2012BAD01B01). 
This article has been published as part of BMC Genetics Volume 15 Supplement 1, 2014: Selected articles from the International Symposium on Quantitative Genetics and Genomics of Woody Plants. The full contents of the supplement are available online at http://www.biomedcentral.com/ bmcgenet/supplements/15/S1.

Published: 20 June 2014

\section{References}

1. Pâues LE, García-Casas MdC, Charpentier JP: Distribution of heartwood extractives in hybrid larches and in their related European and Japanese larch parents: relationship with wood colour parameters. European Journal of Forest Research 2013, 132:61-69.

2. Sun XM, Zhang SG, Zhou DY, Wang XD, Ding B, Liu SM: Phenological variation of Larix species and their intra-species and inter-species hybrid families and early selection. Scientia Silvae Sinicae 2008, 44(1):77-84.

3. Weng YH, Tosh KJ, Park YS, Fullarton MS: Age-related trends in genetic parameters for Jack Pine and their implications for early selection. Silvae Genetica 2007, 56(5):242-251.

4. Gwaze DP, Bridgwater PE, Byram TD, Woolliams JA, Williams CG: Predicting age-age genetic correlations in tree-breeing programs: a case study of Pnius taede L. Theoretical and Applied Genetics 2000, 100:199-206.

5. Lambeth CC, Dill LA: Prediction models for juvenile-mature correlations for loblolly pine growth traits within, between and across test sites. Forest Genetics 2001, 8:101-108.

6. Gwaze DP, Bridgwater PE: Determining the optimum selection age for diameter and height in loblolly pine. Forest Genetics 2002, 9:159-165.

7. Atwood RA, White TL, Huber DA: Genetic parameters and gains for growth and wood properties in Florida source loblolly pine in the southeastern united states. Canadian Journal of Forest Research 2002 32(6):1025-1038

8. Xiang B, Li B, Isik F: Time Trend of Genetic Parameters in Growth Traits of Pinus taeda L. Silvae Genetica 2003b, 52(3-4):114-121.

9. Xiang B, Li B, Mckeand S: Genetic gain and selection efficiency of loblolly pine in three geographic regions. Forest science 2003a, 49(2):196-208.

10. Haapanen M: Time trends in genetic parameter estimates and selection efficiency for Scots pine in relation to field testing method. Forest Genetics 2001, 8:129-144

11. Jansson G, Li B, Hannrup B: Time trends in genetic parameters for height and optimum age for parental selection in Scots pine. Forest Science 2003, 49:696-705.

12. Kroon J, Ericsson $T$, Jansoon G, Andersoon B: Patterns of genetic parameters for height in field genetic tests of Picea abies and Pinus sylvestris in Sweden. Tree Genetics \& Genomes 2011, 7:1099-1111.

13. Kusnandar D, Gwalwey N, Hertzler GL, Butcher TB: Age trends in variance and heritabilities for diameter and height in maritime pine (Pinus pinaster) in western Australia. Slivae Gnetica 1998, 47:136-141.

14. Xie CY, Ying CC: Heritabilities, age-age correlations, and early selection in lodgepole pine (Pinus contorta ssp. latifolia). Silvae Genetica 1996, 45:101-107.

15. Chen $X Y$, Hawkins $B$, Xie $C Y$, Ying CC: Age trends in genetic parameters and early selection of lodgepole pine provenances with particular reference to the lambeth model. Forest Genetics 2003, 10(3):249-258.

16. Riemenschneider DE: Heritability, age-age correlations, and inference regarding juvenile selection in jack pine. Forest Science 1988, 34:1076-1082.

17. Carter KK, Adams GW, Greenwood MS, Nitschke P: Early family selection in jack pine. Canadian Journal of Forest Research 1990, 20:168-175.

18. Jonson GR, Sniezko RA, Mandel NL: Age trends in Douglas-fir genetic parameters and implications for optimum selection age. Silvae Genetica 1997, 46(6):349-358.

19. Dean CA, Stonecypher RW: Early selection of Douglas-Fir across south central Coastal Oregon. USA. Silvae Genetica 2006, 55(3):135-141.

20. Sun XM, Zhang SG, Hou YM, Li SY: Age trends of genetic parameters for growth traits in short rotation Larix kaempferi families. Scientia Silvae Sinicae 2004, 40(6):68-74

21. Ma CG, Zhou TX, Xu JL: A preliminary study on genetic control of growth traits and early selection for Chinese fir (Cunninghamia lanceolata) clones. Scientia Silvae Sinicae 2000, 36:62-69.
22. Sun XM: Selection of superior Larix kaempferi families for pulpwood purpose and family-based growth simulation. Ph. D. Dissertation, Chinese Academy of Forestry, Beijing; 2003, 40

23. Hansen JK, Roulund H: Genetic parameters for spiral grain, stem form, Pilodyn and growth in 13 year old clones of Sitka Spruce (Picea sitchensis (Bong.) Carr.). Silvae Genetica 1996, 46(2-3):107-113.

24. Hai PH, Jansson G, Harwood C, Hannrup B, Thinh HH: Genetic variation in growth, stem straightness and branch thickness in clonal trials of Acacia auriculiformis at three contrasting sites in Vietnam. Forest Ecology and Management 2008, 255:156-157.

25. Isik K, Kleinschmit J, Steiner W: Age-age correlations and early selection for height in a clonal genetic test of Norway spruce. Forest science 2010, 56(2):212-221.

26. Ma SX: Studies on genetic variation and early selection of Japanese larch clones. M. S. Dissertation, Henan Agricultural University, Zhengzhou; 2006, 35 .

27. Houle D: Comparing evolvability and variability of quantitative traits. Genetics 1992, 130:195-204

28. Costa P, Durel CE: Time trend in genetic control over height and diameter in maritime pine. Canadian Journal of Forest Research 1996, 26:1209-1217.

29. King JN, Burdon RD: Time trends in inheritance and projected efficiencies of early selection in a large 17-year-old progeny test of Pinu sradiata. Canadian Journal of Forest Research 1991, 21(8):1200-1207.

30. Vasquez J, Dvorak WS: Trend in variance and heritabilities with stand development of tropical pines. Canadian Journal of Forest Research 1996, , 26: 1473-1480.

31. Danjon F: Heritability and genetic correlations for estimated growth curve parameters in maritime pine. Theoretical. Applied. Genetics 1994, 89:911-921.

32. Li B, Mckeand SE: Genetic parameter estimates and selection efficiency for the loblolly pine breeding in south-eastern U.S. In Tree improvement for sustainable tropical forestry. Queensland, Australia;Dieters M J, Matheson A C, Nikles D G 1996:164-168.

33. Kang $\mathrm{H}$ : Juvenile selection in tree breeding: some mathematical models. Silvae Genetica 1985, 34(2-3):75-84.

34. Ding ZF, Wang JZ, Fang HF, Wang LB, Yu JL, Zou LY, Li CP: The early stage selection technology for family system of Larix olgensis. Journal of Northeast Forest University 1997, 25(3):65-67.

35. Forster GS: Trends in genetic parameters with stand development and their influence on early selection for volume growth in loblolly pine. Forest Science 1986, 32(4):944-959.

36. Lambeth CC, Vanbuijtenen JP, Duke SD: Early selection is effictive in 20year-old genetic tests of loblolly pine. Silvae Genetica 1983, 32(56):210-215

37. Balocchi CE, Bridgwater FE: Age trend in genetic parameters for tree height in a non-selected population of loblolly pine. Forest Science 1993 39:231-251.

38. Zhao CK: A study on optimum age and gain for early selection of superior clone in Cunninghamia lanceolata. Scientia Silvae Sinicae 2002, 38(4):53-60.

doi:10.1186/1471-2156-15-S1-S10

Cite this article as: Lai et al:: Age-related trends in genetic parameters for Larix kaempferi and their implications for early selection. BMC Genetics 2014 15(Suppl 1):S10. 